\title{
Thermodynamic analysis of Spark Ignition engines using the Entropy Generation Minimisation method
}

\author{
Jorge J.G. Martins* and Bernardo S. Ribeiro
}

Department of Mechanical Engineering,

Universidade do Minho,

Campus de Azurém, 4800058 Guimarães, Portugal

E-mail: jmartins@dem.uminho.pt

E-mail: bernardor@dem.uminho.pt

${ }^{*}$ Corresponding author

\section{Ion V. Ion}

Department of Thermodynamics and Heat Engines, University 'Dunarea de Jos' of Galati,

47 Domneasca St., 800008 Galati, Romania

E-mail: ion.ion@ugal.ro

\begin{abstract}
The recent improvement on Spark Ignition Engines has been the result of improved engine thermodynamic cycles, made possible by advances in technologies such as Variable Valve Timing (VVT) and Variable Compression Ratio (VCR). To evaluate the potential of these techniques a thermodynamic analysis is made. Numerical models were implemented in Matlab Simulink using the laws of thermodynamics and include heat transfer, combustion, real working fluid characteristics and intake and exhaust events. The second law analysis allowed the identification of inefficiency sources and directions for improvement. A SI engine was analysed and its processes were evaluated by the amount of entropy generated.
\end{abstract}

Keywords: spark ignition engines; entropy generation minimisation method.

Reference to this paper should be made as follows: Martins, J.J.G., Ribeiro, B.S. and Ion, I.V. (2009) 'Thermodynamic analysis of Spark Ignition engines using the Entropy Generation Minimisation method', Int. J. Exergy, Vol. 6, No. 1, pp.93-110.

Biographical notes: Jorge Jose Gomes Martins is an Associate Professor at the Universidade do Minho, Guimarães, Portugal and the Head of the Laboratory of Internal Combustion Engines. He received his MS in Thermal Engineering from the University of Porto, Portugal, and his $\mathrm{PhD}$ Degree in Internal Combustion Engines from the University of Birmingham, UK. He also works in alternative energies and combustion fields.

Bernardo Sousa Ribeiro is a researcher at the Department of Mechanical Engineering, Universidade do Minho, Guimarães, Portugal. He received his $\mathrm{BS}$ and $\mathrm{PhD}$ in Internal Combustion Engines from the Universidade do Minho, Portugal. His major interests are in the areas of internal combustion engines and energetics. 
Ion $\mathrm{V}$. Ion received his $\mathrm{BS}$ and $\mathrm{PhD}$ in Heat Engines and Equipments from the Mechanical Engineering Faculty of the University 'Dunarea de Jos', Galati, Romania. At present he is an Associate Professor in the Department of Thermodynamics and Heat Engines of the University 'Dunarea de Jos', Galati, Romania. He worked as NATO Advanced Research Fellow at the Laboratory of Internal Combustion Engines, Universidade do Minho, Guimarães, Portugal. His major interests are applied thermodynamics, energy and environmental engineering, thermal solar energy and biomass energy.

\section{Introduction}

Internal combustion engine cycle analysis has recently been made using several methods such as Thermodynamic Second Law analysis (Shapiro and Gerpen, 1989; Bozza et al., 1991; Caton 2000, 2002), Finite Time Thermodynamics (Angulo-Brown et al., 1994; Hernandez et al., 1995, 1996) and Exergy analysis (Lipkea and DeJoode, 1889; Anderson et al., 1998). The Entropy Generation Minimisation (EGM) method used by Bejan (1994, 1996, 1997, 2002) can be applied to power plants and used for the optimisation of systems and processes, leading to EGM as well as to power production maximisation, and also to Internal Combustion Engines (Ribeiro, 2005; Rakopoulos, 2006). It covers heat transfer, mass exchange and thermodynamics. To apply such a method to internal combustion engines it is necessary to identify the various entropy generation mechanisms in an engine related to the above referred entropy generation branches. The motivation to use the EGM method is mainly in the identification of the design variables that lead to entropy generation in the working cycle which, in turn, will enable its reduction from design modifications and alterations of the working parameters. Some basic work on this subject was done by Al-Sarkhi (2005), but he only considered the Miller air standard cycle.

Here, a new model is implemented in order to simulate a Spark Ignition (SI) engine cycle entropy generation using an already existent first law based model. Apart from the entropy generation sources referred to by Bejan, the entropy generation due to combustion will also be considered. Simultaneously, the entropy variation of the system is determined. As referred above, the theoretical treatment of this problem has been widely explored but there are no examples or application cases of the EGM method to internal combustion engines. This application to SI engines aims at the development of a tool for the thermodynamic performances improvement of internal combustion engines.

\section{Entropy generation model}

For the analysis of entropy generation, the control volume shown in Figure 1 is considered as the system. It includes neither the cylinder walls nor the valves. A certain amount of mass upstream and downstream of both valves is also considered as part of the system. In fact, it is clear that there will be some amount of entropy generated from the flow of gases through the valves, which will be accounted for in the total entropy generated by the engine. 
For an open system, the internal entropy variation may be expressed as:

$$
\underbrace{\frac{\mathrm{d} S}{\mathrm{~d} t}}_{\begin{array}{c}
\text { entropy variation } \\
\text { inside the control } \\
\text { volume }
\end{array}}=\underbrace{\sum_{i} \frac{\dot{Q}_{i}}{T_{i}}}_{\begin{array}{c}
\text { entropy variation } \\
\text { due to the heat } \\
\text { transferred }
\end{array}}-\underbrace{\left(\sum_{\text {out }} \dot{m} s-\sum_{\text {in }} \dot{m} s\right)}_{\begin{array}{l}
\text { entropy variation due } \\
\text { to mass flowing in and out } \\
\text { of the control volume }
\end{array}}+\underbrace{\dot{S}_{\text {gen }}}_{\text {entropy generated }} .
$$

Figure 1 Schematic control volume of the analysed system

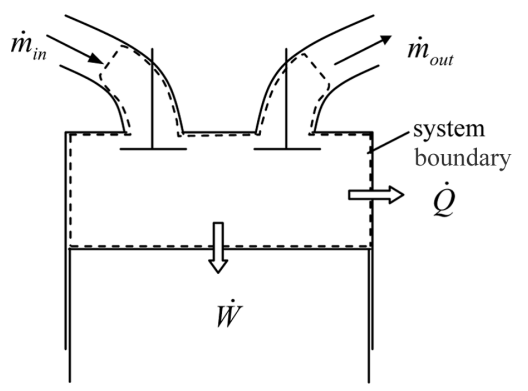

The internal combustion thermal engine cycle (here, we consider the Otto cycle), when theoretically analysed, is composed of an adiabatic compression, followed by a combustion process where heat is supplied to the engine charge at constant volume. The latter process is expected to show an important rise in the entropy of the system. After combustion, an adiabatic expansion and a cooling process brings the system back to the initial point of the cycle. The entropy generation variation within the theoretic Otto cycle is shown in a $T-S$ diagram (Figure 2 ).

Figure $2 T-S$ diagram for a theoretical process of the Otto cycle

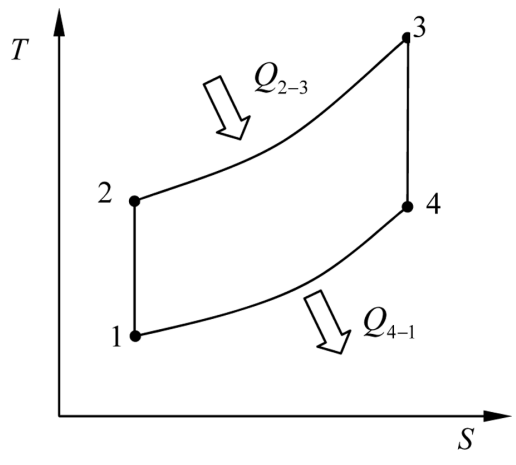

Figure 2 does not represent the real indicated diagram of an internal combustion engine. However, for the processes between points 1 and 4 (compression, combustion and expansion) the entropy variation of the theoretical and real cycles are similar. The actual cooling process between 4 and 1 cannot be compared with that of the theoretical cycle, because real engines are modelled as open systems where mass flows in and out of the system, which leads to a $T-S$ diagram quite different from the theoretical one.

The entropy variation of a process is equal to the sum of three components, the entropy variation through heat and fluid flow to the surroundings, plus the entropy 
generated due to the irreversibilities of various thermodynamic processes taking place inside the system. Figure 3 shows the difference between a theoretical and a real heating process. In both situations a variation in the entropy of the system is expected. However, the final entropy (at point 3 and $3^{\prime}$ ) is not the same. This is due to the entropy generated during the real process between 2 and $3^{\prime}$.

Figure 3 Comparison of a theoretical and a real heating process

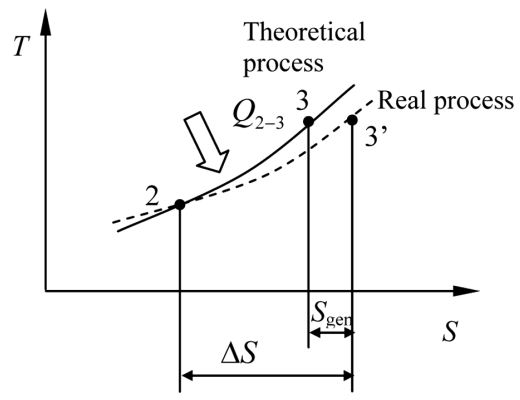

To calculate the total entropy generation rate of the entire system we can proceed to summing up the entropy generated due to each particular irreversibility mechanism. This approach enables observing the direct interaction between various design concepts and the irreversibilities (Nakonieczny, 2002).

\subsection{Heat transfer}

During the entire engine cycle there is some heat flux between the gases contained inside the cylinder and the various walls. Usually, during the intake, the flux is from the cylinder walls to the gas, due to the higher temperature of the walls in relation to the mixture temperature (near ambient temperature). During the remainder of the cycle, the heat flux is from the hot gases to the cylinder walls. As the process is the result of a finite temperature difference, some amount of generated entropy is expected. The entropy generated in this process can be defined as the sum of the entropy variations of the system and the surroundings, expressed as (Çengel and Boles, 1998):

$$
S_{\text {gen }}=\Delta S_{\text {total }}=\Delta S_{\text {system }}+\Delta S_{\text {surroundings }} \text {. }
$$

The expression for the calculation of the generated entropy is then defined as the difference between the entropy variation of the wall and the entropy variation of the gas. The entropy generation rate due to heat transfer is expressed as:

$$
\dot{S}_{\text {gen,heat }}=\frac{\dot{Q}}{T_{w}}-\frac{\dot{Q}}{T_{\text {gas }}} \geq 0
$$

where $\dot{Q}$ is the heat flux transferred across the system boundaries (cylinder liner, piston crown and engine head), which will be negative when the heat flux leaves the system and positive when it comes into the system. Being a function of the crank angle $(\theta)$, it is calculated as: 


$$
\frac{\delta Q}{\mathrm{~d} \theta}=\frac{\alpha A\left(T_{\mathrm{gas}}-T_{w}\right)}{6 N} .
$$

The heat transfer coefficient, $\alpha$ is calculated following the method presented by Annand (Blair, 1999).

\subsection{Flow through valves}

The stream through the valves suffers a pressure drop due to the local resistance, depending on the valve and duct geometry. Some of the work produced by the engine is used to overcome this resistance to fluid flow. The entropy generated in this process may then be seen as the work lost to perform the admission or the exhaust of the mass. Considering a quasi-steady gas flow through the valve, the entropy generation rate can be calculated from the upstream $(u)$ and downstream $(d)$ (of the valves) state properties and the average value of the gases' Mach number $(M)$ at valve inlet, as follows:

$$
\begin{aligned}
\dot{S}_{\text {gen, value }} & =\dot{m} \int_{c}^{p} \mathrm{~d} s=\dot{m}\left[c_{p} \ln \left(\frac{T_{u}}{T_{d}}\right)-R \ln \left(\frac{p_{u}}{p_{d}}\right)\right] \\
& =\dot{m}\left[c_{p} \ln \left(1-\frac{k-1}{2} M^{2}\right)+c_{p} \frac{k-1}{k} \ln \left(\frac{p_{u}}{p_{d}}\right)\right] \\
& =\dot{m} c_{p} \ln \left[\left(1-\frac{k-1}{2} M^{2}\right)\left(\frac{p_{u}}{p_{d}}\right)^{\frac{k-1}{k}}\right] .
\end{aligned}
$$

\subsection{Viscous friction}

Apart from the pressure drop referred above due to the flow through the valves, there is also a pressure drop due to the viscous friction during intake and exhaust. This also induces a pressure drop inside the cylinder. The entropy generation associated with the viscous friction in the flow during the admission/exhaust process can be written (Bejan, 1994) as:

$$
\dot{S}_{\mathrm{gen}, \mathrm{adm} / \mathrm{exh}}=\dot{S}_{\mathrm{gen}, \Delta p}=\frac{2 \dot{m}^{3} f \cdot L}{\rho^{2} D \cdot A^{2} T} .
$$

The friction factor does not have a linear behaviour; it will be a function of the regime of fluid flow inside the cylinder (laminar or turbulent) and it will depend on the value of the Reynolds number. So, the value of the friction factor will be calculated in the following manner:

$$
\begin{array}{ll}
\text { For laminar flow regime }\left(\operatorname{Re} \leq 5 \times 10^{3}\right): & f=16 / \mathrm{Re} \\
\text { For transitory flow regime }\left(5 \times 10^{3}<\operatorname{Re} \leq 3 \times 10^{4}\right): & f=0.079(\mathrm{Re})^{-0.25} \\
\text { For turbulent flow regime }\left(3 \times 10^{4}<\operatorname{Re}<10^{6}\right): & f=0.046(\mathrm{Re})^{-0.2 .}
\end{array}
$$




\subsection{Free expansion during exhaust}

An important entropy generating process in an internal combustion engine is the release of the exhaust gases during the exhaust stroke, especially during the blow-down phase, where gases under high temperature and pressure are freely released to the atmosphere without producing any work. As stated by the Gouy-Stodola theorem, the entropy generated is equal to the lost work divided by the environment temperature.

$$
W_{\text {lost }}=T_{0} \cdot S_{\text {gen }} \text {. }
$$

In this case the work lost is represented by the enthalpy of the gases that flow out of the engine at a different state than the environment. The entropy generation rate is calculated by Bejan (1997):

$$
\dot{S}_{\text {gen,enthalpy }}=\sum_{\text {in }} \frac{\dot{m}}{T_{0}}\left(h-h_{0}\right)-\sum_{\text {out }} \frac{\dot{m}}{T_{0}}\left(h-h_{0}\right) .
$$

\subsection{Combustion}

The combustion process (process 2-3 in the theoretical Otto cycle), is characterised by a significant entropy generation due to two main processes:

- the chemical reaction that converts the mixture of fuel and air into a mixture of burned gases (here considered only $\mathrm{CO}_{2}, \mathrm{~N}_{2}$ and $\mathrm{H}_{2} \mathrm{O}$ )

- the release of heat.

So, for combustion, function of combustion products $(p)$ and reactants state properties $(r)$, the entropy generation rate is:

$$
\dot{S}_{\mathrm{gen}, \mathrm{comb}}=\sum_{i=1}^{n} \dot{n}_{p i} \bar{s}_{p i}-\sum_{i=1}^{m} \dot{n}_{r i} \bar{S}_{r i}=\dot{S}_{3}-\dot{S}_{2}
$$

where $\dot{S}_{2}, \dot{S}_{3}$ is the entropy rate corresponding to the reactants (air and fuel) and combustion products, respectively:

$$
\begin{aligned}
& \dot{S}_{2}=\dot{m}_{a} s_{a}\left(T_{2}, p_{2}\right)+\dot{m}_{f} s_{f}\left(T_{2}, p_{2}\right) \\
& \dot{S}_{3}=\sum_{k} \dot{m}_{k} s_{k}\left(T_{3}, p_{3}\right) .
\end{aligned}
$$

The specific entropy of each chemical species is calculated at the instantaneous temperature inside the cylinder.

The entropy of the several chemical species present in the system is calculated by the following expressions (Ferguson, 1986):

- $\quad$ air entropy

$$
\begin{aligned}
s_{a}(T, p)= & s^{0}\left(T, p_{0}\right)-R_{a} \ln \frac{p}{p_{0}}=-4.7306 \cdot 10^{-14} T^{4}+3.9579 \cdot 10^{-10} T^{3} \\
& -1.3797 \cdot 10^{-6} T^{2}+2.9099 \cdot 10^{-3} T+1.089-0.287 \ln \frac{p}{p_{0}}
\end{aligned}
$$


- fuel entropy

$$
\begin{aligned}
s_{f}(T, p)= & s_{f}^{0}\left(T, p_{0}\right)-R_{f} \ln \frac{p}{p_{0}}=\int_{0}^{T} c_{p} \frac{d T}{T}-R_{f} \ln \frac{p}{p_{0}} \\
= & R_{f}\left(-\frac{1}{2} 1.8801 \cdot 10^{-5} T^{2}+6.0977 \cdot 10^{-2} T+4.0652 \ln T+15.45\right) \\
& -R_{f} \ln \frac{p}{p_{0}} .
\end{aligned}
$$

The exhaust gases' specific entropy is calculated by (using Table 1):

$$
\begin{aligned}
& s_{k}\left(T, x_{k} p\right)=s_{k}^{\prime}\left(T, p_{0}\right)-R_{k} \ln \left(\frac{x_{k} p}{p_{0}}\right) \\
& s_{k}^{\prime}\left(T, p_{0}\right)=A+B T+C T^{2}+D T^{3}+E T^{4} .
\end{aligned}
$$

Table 1 Coefficients for the calculation of the specific entropy of exhaust gases

\begin{tabular}{lccccc}
\hline Substance & $A$ & $B$ & $C$ & $D$ & $E$ \\
\hline $\mathrm{CO}_{2}$ & 3.9935 & $3.5272 \times 10^{-3}$ & $-2.0162 \times 10^{-6}$ & $7.2219 \times 10^{-10}$ & $-1.0832 \times 10^{-13}$ \\
$\mathrm{H}_{2} \mathrm{O}$ & 9.4485 & $5.0705 \times 10^{-3}$ & $-2.0933 \times 10^{-6}$ & $5.5747 \times 10^{-10}$ & $-6.1112 \times 10^{-14}$ \\
$\mathrm{~N}_{2}$ & 5.9128 & $4.0464 \times 10^{-3}$ & $-2.7234 \times 10^{-6}$ & $1.0822 \times 10^{-9}$ & $-1.7318 \times 10^{-13}$ \\
\hline
\end{tabular}

Source: Çengel and Boles (1998)

\subsection{Overall entropy generation}

In the account of the entropy variation of the system, the entropy generating processes already described should be considered, as well as the entropy variation due to the heat flux and the mass exchange mechanisms.

For the analysis of entropy generation, the control volume shown in Figure 1 is considered as the system. It includes neither the cylinder walls nor the valves. A certain amount of mass upstream and downstream of both valves is also considered as part of the system. In fact, it is clear that there will be some amount of entropy generated from the flow of gases through the valves, which will be accounted for in the total entropy generated by the engine.

For the elementary system, the entropy variation with respect to the crank angle $(\theta)$, is:

$$
\frac{\mathrm{d} S}{\mathrm{~d} \theta}=\frac{\mathrm{d} S_{\mathrm{gen}}}{\mathrm{d} \theta}+\frac{1}{T_{w}} \frac{\delta Q}{\mathrm{~d} \theta}-\frac{1}{6 N}\left(\frac{\mathrm{d} m_{\mathrm{out}}}{\mathrm{d} \theta} S_{\mathrm{out}}-\frac{\mathrm{d} m_{\mathrm{in}}}{\mathrm{d} \theta} S_{\text {in }}\right) .
$$

Solving the thermodynamic model numerically we can calculate the entropy generated by each source of irreversibility. Summing up the quantities of generated entropy we obtain the total entropy generated during engine operation. 


\section{Numerical models}

Using the Matlab Simulink tool, a theoretical model was implemented based on the first law of thermodynamics and on the ideal gas equation. Other models were added to this baseline model in order to simulate the other phenomena present in a SI engine. Thus, the Annand model was used for heat transfer and the Wiebe expression (Heywood, 1988) was used for combustion and heat release. As, during compression, combustion and expansion the composition and characteristics of the gas change, a model for the instantaneous calculation of specific heats and gas constants of all chemical species was used, considering stoichiometric mixture at the intake and complete combustion. It was also necessary to simulate the mass flow through the valves using discharge coefficients (Martins, 2005).

The model for calculation of the entropy generated in each cycle, as described above, was based on a time step routine similar to that used for the first law model and was implemented in Matlab Simulink.

\section{Results and discussion}

For the present example a single cylinder engine was modelled with the characteristics presented in Table 2.

Table 2 Engine model specifications

\begin{tabular}{ll}
\hline Bore & $80 \mathrm{~mm}$ \\
Displacement & $211 \mathrm{~cm}^{3}$ \\
Compression ratio & 12 \\
Speed & $3000 \mathrm{rpm}$ \\
Intake Valve Opening & $20^{\circ}$ before TDC \\
Intake Valve Closing & $42^{\circ}$ after BDC \\
Exhaust Valve Opening & $40^{\circ}$ before BDC \\
Exhaust Valve Closing & 12 after TDC \\
Intake Valve Diameter & $30 \mathrm{~mm}$ \\
Exhaust Valve Diameter & $25 \mathrm{~mm}$ \\
Intake Valve Lift & $7.2 \mathrm{~mm}$ \\
Exhaust Valve Lift & $7.2 \mathrm{~mm}$ \\
\hline
\end{tabular}

Calculating all the modes of entropy generation presented above, the importance of each part is shown in Figure 4.

With this diagram it is possible to establish a hierarchy of the entropy generation mechanisms and analyse each one, leading to a reduction of the entropy generated in each thermal cycle of a SI engine. A detailed analysis of each entropy generation mechanism is presented in the next sections. Based on the results obtained in this analysis and in order to reduce the entropy generation, design and operating solutions are proposed. 
Figure 4 Contribution of each entropy generation mechanism

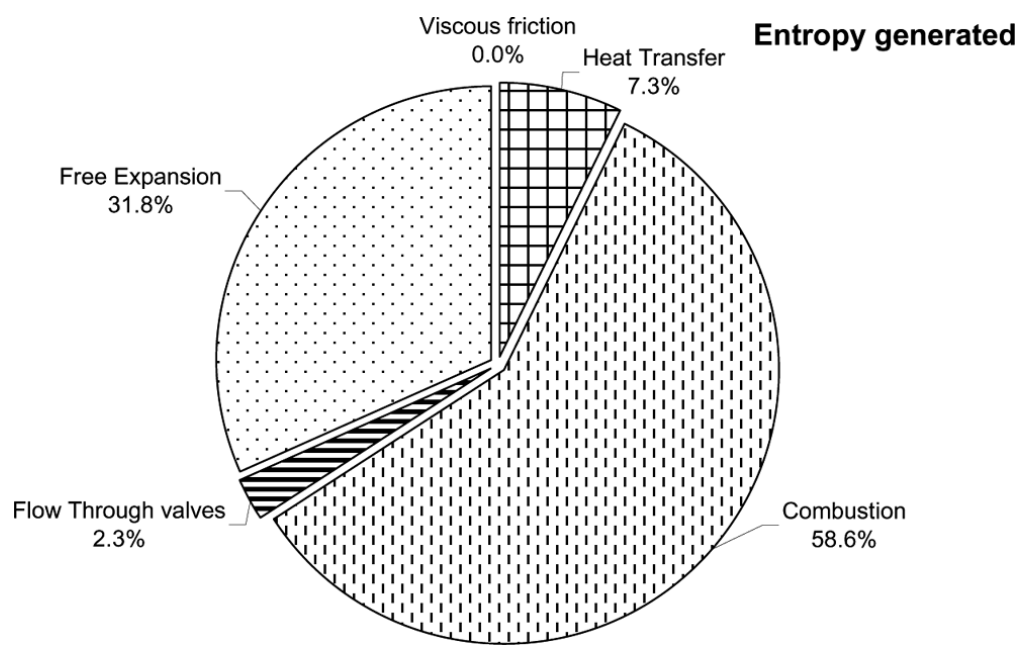

\subsection{Heat transfer}

The heat gained or lost by the engine charge is transferred to and from the cylinder walls, piston head and engine head. All these components have different surface temperatures, but they are considered constant during the overall cycle (mean wall temperature for each surface). The entropy generated due to this mechanism is only dependent on the wall temperature, its area and on the heat flux from, and to, the engine charge. This heat flux depends on the temperature difference between gases and wall and the heat transfer coefficient. From the above discussion it is possible to conclude that a reduction on the temperature gradient between the gases and walls leads to a reduction of the entropy generated.

The entropy generation rate profile due to heat transfer during the thermal engine cycle is shown in Figure 5. As can be seen, the highest rate of entropy generation occurs at the highest temperature of the cycle (combustion process). This is the point where the difference between the temperature inside the cylinder and the temperature of the engine walls is highest. During the intake and combustion process there are two points with no entropy generation that correspond to the points where the temperature of the mixture inside the engine equals the temperature of the cylinder walls.

A reduction of entropy generation by heat transfer can be achieved by adjusting the wall temperatures to the charge temperatures, raising the wall temperatures during combustion and expansion, and lowering them during compression and intake. However, this may prove to be impractical, because the walls will have constant temperature and there is also a limitation to the wall temperature by the onset of knock.

The combustion chamber geometry can also influence the generated entropy, because a compact combustion chamber has less area for heat transfer, reducing the rate of heat transfer. This effect can be achieved using higher compression ratios (although other problems may occur). An engine with a high stroke/bore ratio should also reduce the total heat transferred, by using a smaller combustion chamber. In fact, the volume variation at top dead centre (TDC) is smaller and the cylinder area exposed during the high temperatures period is smaller, reducing the heat transfer rate. 
Figure 5 Entropy generation rate due to heat transfer

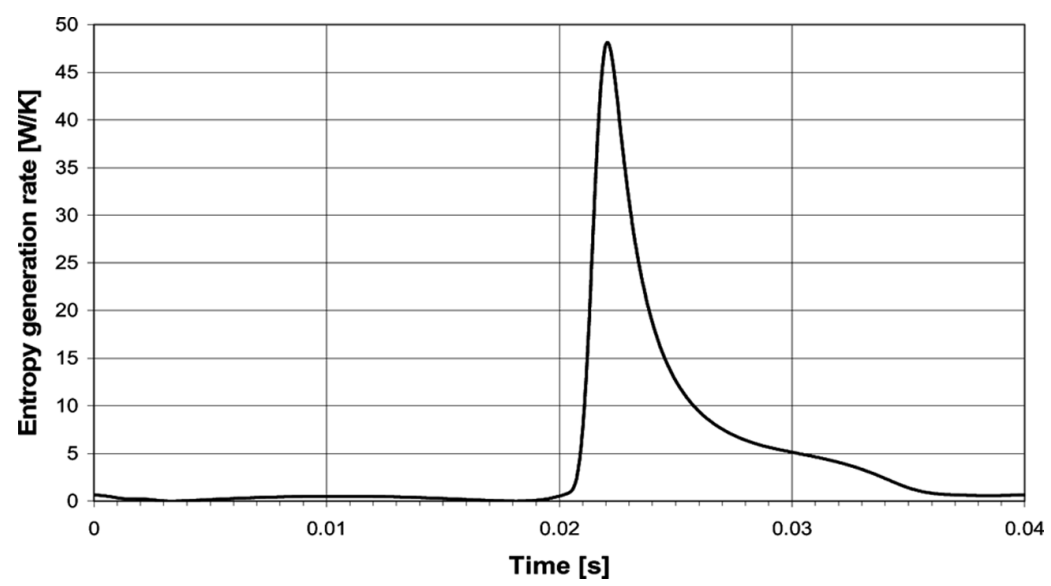

The maximum temperatures achieved by using the lean mixtures, Exhaust Gas Recirculation (EGR) or throttled operation are lower than at full throttle and stoichiometric conditions that leads to smaller entropy generation rates during the thermal engine cycle. These methods have other effects as dissociation, $\mathrm{NO}_{\mathrm{x}}$ formation, which leads to entropy generation change.

\subsection{Combustion}

The entropy generated in the combustion is due to the chemical reactions that occur during this process. Before the combustion, there is a certain amount of air and fuel mixture at a certain temperature and pressure inside the engine cylinder. As combustion takes place, there is a conversion of chemical species, and also an increase of pressure and temperature. It is considered that the entire mixture of air and fuel reacts entirely, generating burned gas species, such as $\mathrm{H}_{2} \mathrm{O}$ and $\mathrm{CO}_{2}$. As a consequence of the temperature rise, the specific heats of air, fuel, and burned gas species increase in a significant manner, increasing the values of the specific entropy of each chemical component. As shown above in equations (11)-(13), the entropy depends also on the logarithm of the ratio between the pressure inside the engine (which increases significantly) and the environment pressure. The entropy generation rate profile for this process is shown in Figure 6. As can be seen, the generation rate has an increasing part and a decreasing part, following the Wiebe function that is used to describe the combustion process in the First Law model. The peak value for combustion is nearly 30 times higher than for heat transfer.

The reduction of the entropy variation during this process may be achieved by combustion at higher temperatures (and pressures). In fact, a simulation was made with a compression ratio of 8.5 instead of 12 and a slight increase of entropy generated was noticed, showing a lower thermal efficiency.

Changing the burning parameters (burn duration or spark timing) may also influence the entropy generated during combustion, mainly due to the change of reaction temperatures. Faster combustions lead to higher maximum temperatures. The same effect is achieved with shorter spark advances. Most of these parameters are limited by the onset of knock and thus the EGM in SI engines is strongly limited by knock. 
Figure 6 Entropy generation rate due to the combustion process

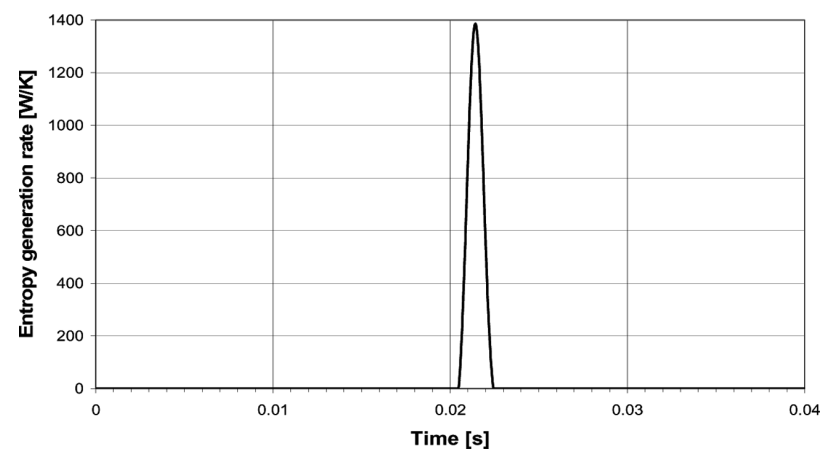

The use of lean mixtures may reduce the total entropy generated during combustion as the lower ratio fuel/total mass in each cycle is smaller, leading to lower temperatures and lower values for the constant pressure specific heat $\left(c_{p}\right)$. The same effect happens when EGR is used.

Other chemical processes, such as dissociation or $\mathrm{NO}_{\mathrm{x}}$ formation, influence the entropy generation rate, but they were not considered in this model.

\subsection{Free expansion}

After expansion, when the exhaust valve opens, the burned gases enclosed within the cylinder are still at high temperature and pressure. Some of the enthalpy could be converted into work if expansion endures up to the atmospheric pressure. This may be achieved by using an over-expanded engine, where the expansion stroke is longer than the intake or the compression strokes. But even in this case a certain amount of entropy would be generated because the gases would be at high temperature.

The entropy generation rate due to the release of high enthalpy gases is presented in Figure 7. The right side of the plot corresponds to the exhaust stroke, while the left side corresponds to the back-flow to the intake manifold. The main contribution of this entropy generating process is made during the blow-down (exhaust phase) where real high enthalpy gases are released to the environment. In the computer model it is considered that the intake mixture is always at atmospheric pressure and temperature. Although the peak value in free expansion is almost nine times smaller than during combustion, the total (integrated) value of the generated entropy is over $50 \%$ of that one.

Figure 7 Entropy generation rate due to enthalpy loss

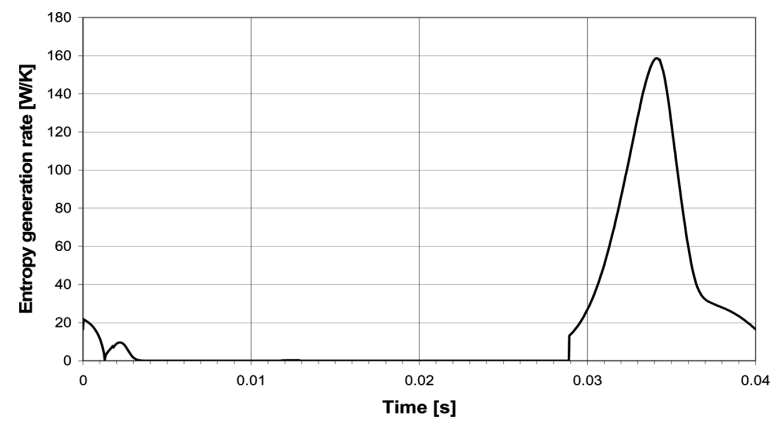




\subsection{Flow through the valves}

The entropy generated by the flow of the intake mixture or the exhaust gases through the intake and exhaust valves, is due to the pressure difference needed to generate the flow. In fact, when the valves are open, some work generated by the engine is used for pumping the mixture and the exhaust gases. As can be seen in equation (5), the rate of entropy generation depends on the pressure ratio, the valve cross section area and the pipe cross section after the valve (during exhaust).

The entropy generation rate due to the flow through the valves is presented in Figure 8. As can be seen, the entropy generation rate during exhaust (right side of plot) is much higher than during intake (left side of plot), mainly because of the high pressure of the burned gases inside the cylinder that leads to a high speed flow through the exhaust valve. Also, the fact that the specific entropy of the exhausted gases at the exhaust temperature is significantly higher than the specific entropy of the intake mixture leads to a higher value of entropy generation rate through the exhaust valve.

Figure 8 Entropy generation rate due to the flow of gases through the valves

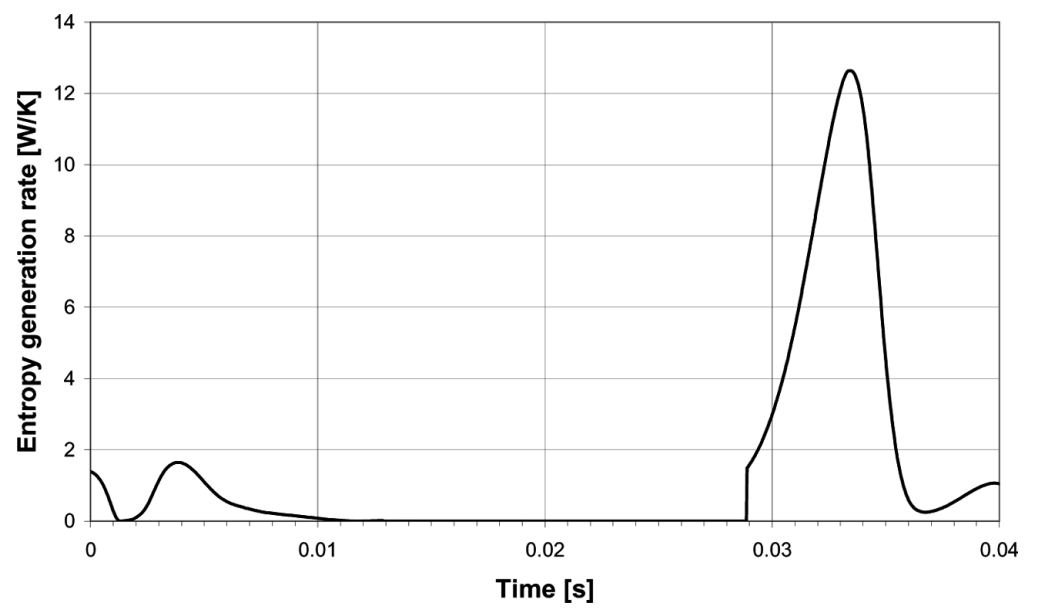

Again, in this case, the reduction of pressure and temperature of the exhaust gases is an important means of reducing the entropy generation rate and the total entropy generated.

\subsection{Viscous friction inside cylinder during mass transfer processes}

This is the least important component of the entropy generation process. From Figure 4 one can see that the entropy generation rate due to internal viscous friction is very small when compared to the other components previously analysed, so it can be neglected.

The lack of continuity on the graph plotted in Figure 9 is due to the fact that the friction factor, as mentioned in equation (6), is not a continuous function of the Reynolds number. 
Figure 9 Entropy generation rate due to internal viscous friction

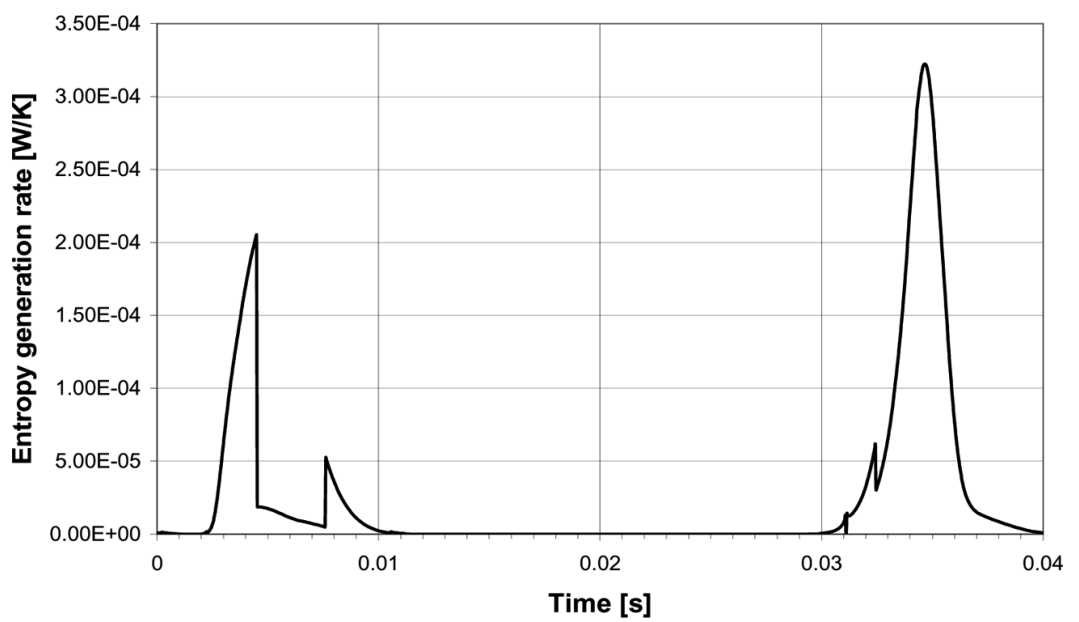

The peak values observed in Figure 9 correspond to peak values of the mass flow rate. During intake this peak is not continuous, due to a higher value of the Reynolds number, which led to a smaller value of the friction factor.

\subsection{Overall entropy generated in an irreversible thermal cycle}

The integration of the total value of entropy generated during the irreversible Otto thermal cycle is shown in Figure 10, as well as the importance of each entropy generating process.

The entropy generation during compression (first $7 \mathrm{~ms}$ ) is insignificant compared to the entropy generated during other cycle phases. During combustion there is a significant increase in the entropy generated, not only due to the combustion itself, but also due to the heat transfer. Heat transfer also increases in the subsequent steps of the engine cycle, especially during expansion, due to the high heat transfer coefficient and temperature difference to the walls. When the exhaust valve opens, a phase of great entropy generation starts, due to the exhaust of gases at high temperature and pressure to the atmosphere, and also due to the gas flow through the valves and the discharge processes. When the cycle finishes (40 ms, Figure 10), the entropy generated reaches the value of $2.4 \mathrm{~J} / \mathrm{K}$ in one cycle. At the same time, in Figure 10 it is possible to see that the influence of the viscous friction of the fluid is negligible $\left(1.05 \times 10^{-6} \mathrm{~J} / \mathrm{K}\right)$ in this kind of engines and under these conditions.

Looking at the $T-S_{\text {gen }}$ calculated diagram of the considered irreversible Otto thermal cycle (Figure 11), the total generated entropy referred above is shown in subsequent cycles. Once more, it can be seen that the combustion and the free expansion during the exhaust are the main entropy generating processes. During intake and compression the entropy generated is almost insignificant. 
Figure 10 Total amount of entropy generated per considered irreversible Otto cycle

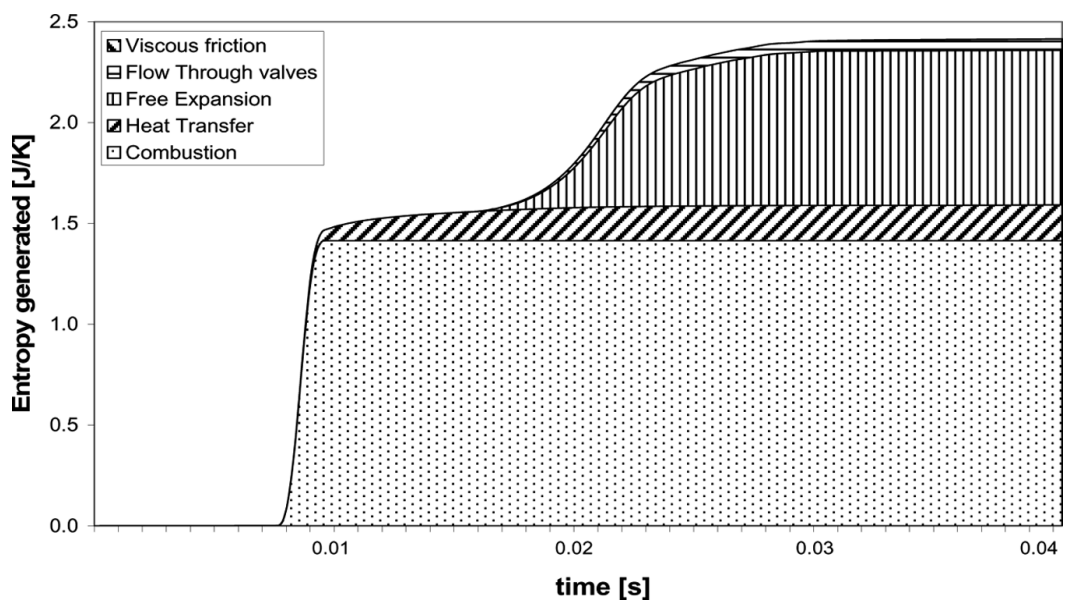

Figure 11 Entropy generated during the considered irreversible Otto cycle

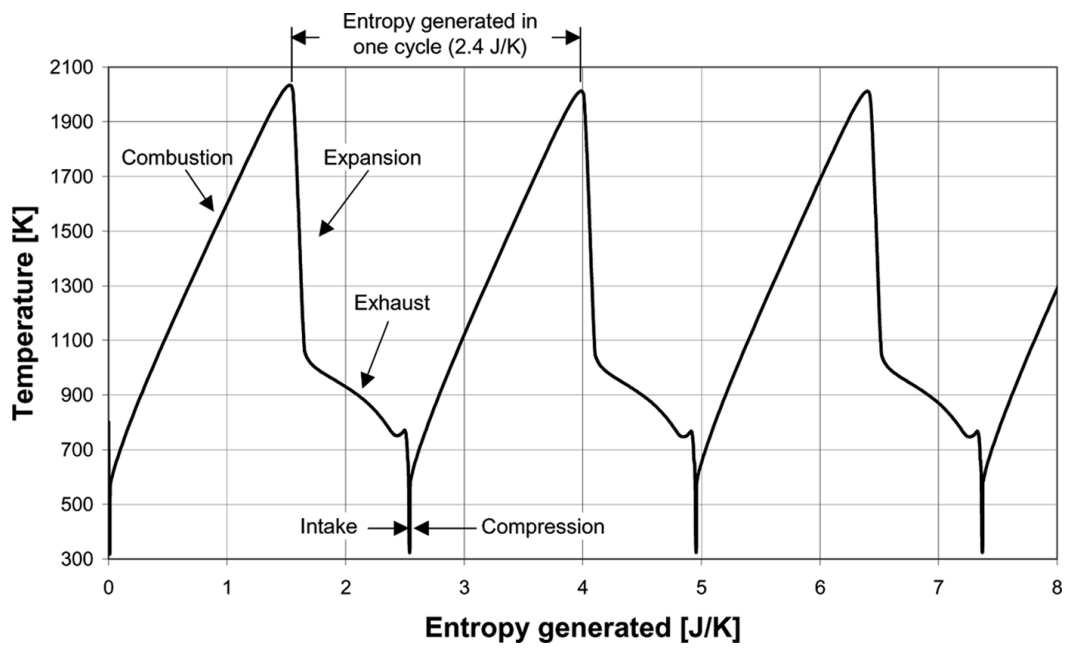

\subsection{Entropy variation}

Inside the cylinder some of the entropy variations do not correspond to entropy generation, as there are entropy variations due to mass and heat exchange with the surroundings, so the entropy variation can be expressed as follows:

$$
\underbrace{\Delta S_{\text {system }}}_{\begin{array}{c}
\text { entropy } \\
\text { variation }
\end{array}}=\underbrace{S_{\text {in }}-S_{\text {out }}}_{\begin{array}{c}
\text { entropy transfer through } \\
\text { mass and heat exchange }
\end{array}}+\underbrace{S_{\text {gen }}}_{\begin{array}{c}
\text { entropy } \\
\text { generated }
\end{array}} .
$$

The entropy elementary variation due to the mass exchange is described as a rate, as:

$$
\frac{\mathrm{d} S}{\mathrm{~d} \theta}=\frac{\mathrm{d} m_{\text {in }}}{\mathrm{d} \theta} S_{\text {in }}-\frac{\mathrm{d} m_{\text {out }}}{\mathrm{d} \theta} S_{\text {out }}
$$


where the elementary mass quantities, $\mathrm{d} m$ are inputs from the first law model, and $s_{\text {in }}$ and $s_{\text {out }}$ are calculated as described in equation (10).

The elementary entropy variation due to the heat exchange is expressed as:

$$
\frac{\mathrm{d} S}{\mathrm{~d} \theta}=\sum \frac{1}{T_{l}} \frac{\delta Q_{l}}{\mathrm{~d} \theta}
$$

where $\delta Q_{l}$ is the heat transfer rate through the $l$ borders and $T_{l}$ is the surrounding temperature.

The generated entropy component from equation (16) is the overall generated entropy calculated by the sum of the entropy generated by all the processes described above.

The $T-S$ diagram for the considered irreversible Otto thermal cycle described in this paper is shown in Figure 12.

Figure $12 T-S$ diagram of the considered irreversible Otto cycle

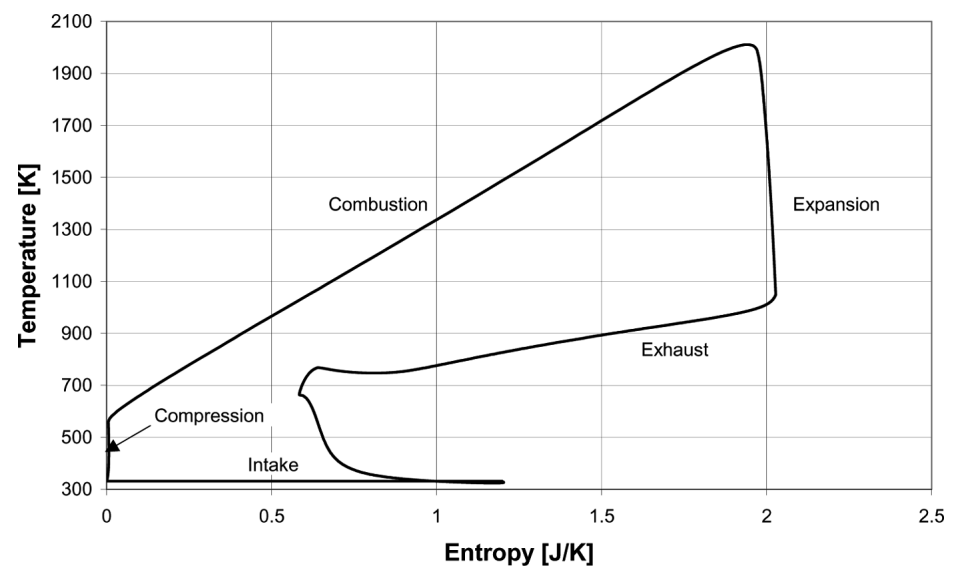

Comparing this diagram with the one of the theoretical Otto thermal cycle (Figure 2) some similarities can be observed. The irreversible compression process in the irreversible thermal cycle $T-S$ diagram also has an almost vertical line, similar to the isentropic transformation 1-2. As expected, the heat supply (combustion) in the irreversible thermal cycle increases the system's entropy significantly, more than in the theoretical process 2-3. In the irreversible expansion process the entropy shows a small increase, similar to the isentropic transformation 3-4. The cooling process of the irreversible thermal cycle shows a significant difference with respect to the theoretical process 4-1. In the irreversible thermal cycle $T-S$ diagram (Figure 12) the cooling phase includes mass exchange processes (exhaust and intake) and these give a different shape to the diagram.

\section{Conclusions}

A mathematical model for the entropy generation computation in an internal combustion thermal engine was developed and implemented in a MatLab Simulink program. The model includes the generation of entropy by combustion, heat transfer, free expansion, mass flow through the valves and viscous friction inside the engine. 
This mathematical model is an extension of an existing thermodynamic computer model based on the first law of thermodynamics.

The results obtained from the described model allow the use of the EGM method, which identifies the entropy sources within the thermodynamic engine cycle.

This computer model was applied to the Otto cycle and the results obtained for a certain thermal engine model were discussed.

Based on the computation of entropy variation and generation in the all irreversible process that occur inside the system, it was possible to obtain the irreversible Otto thermal cycle in a $T-S$ diagram for the considered thermal engine model. It shows that combustion is the mechanism responsible for nearly $54 \%$ of the total entropy generated. Free expansion of the exhaust gases, heat transfer and mass flow through valves are the next mechanisms of importance of the entropy generation in this thermal engine. The results also show that the viscous friction of the working fluid inside the engine has no significant impact on the total amount of generated entropy.

The identification of the entropy generation processes works as inputs in the engine design optimisation process, helping to define the best paths to improve the engine thermodynamic performances. It was noticed that the enthalpy losses due to the exhaust gases is the process where major improvements can be made to a thermal engine.

\section{References}

Al-Sarkhi, Jaber, J.O. and Probert S.D. (2006) 'Efficiency of a Miller engine', Applied Energy, Vol. 83, pp.153-165.

Anderson, M.K., Assanis, D.N. and Filipi, Z.S. (1998) First and Second Law Analyses of a Naturally-Aspirated, Miller Cycle, SI Engine with Late Intake Valve Closure, SAE 980889.

Angulo-Brown, F., Fernández-Betanzos, J. and Diaz-Pico C.A. (1994) 'Compression ratio of an optimized air standard Otto-cycle model', Eur. J. Phys., Vol. 15, pp.38-42.

Bejan, A. (1994) Entropy Generation through Heat and Fluid Flow, John Wiley\& Sons, New York.

Bejan, A. (1996) Entropy Generation Minimization, CRC Press, Boca Raton.

Bejan, A. (1997) Advanced Engineering Thermodynamics, 2nd ed., John Wiley \& Sons, New York.

Bejan, A. (2002) 'Fundamentals of exergy analysis, entropy generation minimization, and the generation of flow architecture', Int. J. Energy Res., Vol. 26, pp.545-565.

Blair, G.P. (1999) Design and Simulation of Four-Stroke Engines, SAE 978-0-7680-0440-3.

Bozza, F., Nocera, R., Senatore, A. and Tuccilo, R. (1991) Second Law Analysis of Turbocharged Engine Operation, SAE 910418.

Hernandez, A.C., Medina, A., Roco, J.M.M. and Velasco, S. (1995) 'On an irreversible air standard Otto-cycle model', European Journal of Physics, Vol. 16, pp.73-75.

Hernandez, A.C., Roco, J.M.M., Medina, A. and Velasco, S. (1996) 'An irreversible and optimised four stroke cycle model for automotive engines', European Journal of Physics, Vol. 17, pp.11-18.

Caton, J.A. (2000) A Review of Investigations Using the Second Law of Thermodynamics to Study Internal Combustion Engines, SAE 2000-01-1081.

Caton, J.A. (2002) A Cycle Simulation Including the Second Law of Thermodynamics for a Spark-Ignition Engine: Implications of the Use of Multiple-Zones for Combustion, SAE 2002-01-0007.

Çengel, Y.A. and Boles, M.A. (1998) Thermodynamics: An Engineering Approach, 3rd ed., WCB McGraw-Hill, Boston. 
Ferguson, C.R. (1986) Internal Combustion Engines, Applied Thermosciences, John Wiley \& Sons, New York.

Hernandez, A.C., Medina, A., Roco, J.M.M. and Velasco, S. (1995) 'On an irreversible air standard Otto-cycle model', Eur. J. Phys., Vol. 16, pp.73-75.

Hernandez, A.C., Roco, J.M.M., Medina, A. and Velasco, S. (1996) 'An irreversible and optimized four stroke cycle model for automotive engines', Eur. J. Phys., Vol. 17, pp.11-18.

Heywood, J.B. (1988) Internal Combustion Engine Fundamentals, McGraw-Hill, London.

Lipkea, W.H. and DeJoode, A.D. (1889) A Comparison of the Performance of Two Direct Injection Diesel Engines from a Second Law Perspective, SAE 890824.

Martins, J. (2005) Motores de Combustão Interna, Publindústria, Porto (in Portuguese).

Martins, J. and Ribeiro, B. (2007) Direct Comparison of an Engine Working under Otto, Miller and Diesel Cycles: Thermodynamic Analysis and Real Engine Performance, SAE 2007-01-0261.

Martins, J., Uzuneanu, K. and Ribeiro, B. (2004) Thermodynamic Analysis of an Over-Expanded Engine, SAE 2004-01-0617.

Nakonieczny, N. (2002) 'Entropy generation in a diesel engine turbocharging system', Energy, Vol. 27, pp.1027-1056.

Nilsson, Y., Eriksson, L., Gunnarsson, M. (2006) A Model for Fuel Optimal Control of a Spark-Ignited Variable Compression Engine, SAE 2006-01-0399.

Rakopoulos, C.D. and Giakoumis, E.G. (2006) 'Second-law analyses applied to internal combustion engines operation', Progress in Energy and Combustion Science, Vol. 32, pp. $2-47$.

Ribeiro, B. and Martins, J.J.G. (2005) 'Miller cycle analysis using EGM', 2005 Fall Conference of the ASME Internal Combustion Engine Division (proceedings on CD), Ottawa, Canada, 11-14 September.

Shapiro, H.N. and Gerpen, J.V. (1989) Two Zone Combustion Models for Second Law Analysis of Internal Combustion Engines, SAE 890823.

Torella, E., Galloni, E., Palmaccio, R. and Fontana, G. (2006) The Influence of Variable Valve Timing on the Combustion Process of a Small Spark-Ignition Engine, SAE 2006-01-0445.

\section{Nomenclature}

\begin{tabular}{ll}
\hline$A$ & Cross section area of cylinder $\left(\mathrm{m}^{2}\right)$ \\
BDC & Bottom Dead Centre \\
$c_{p}$ & Constant pressure specific heat $(\mathrm{kJ} /(\mathrm{kg} \mathrm{K}))$ \\
$D$ & Cylinder diameter $(\mathrm{m})$ \\
$\mathrm{d} X$ & Elementary variation of ' $X$ ' state parameter \\
$\delta X$ & Elementary exchange of ' $X$ ' transferred energy $(\mathrm{J})$ \\
$\Delta X$ & Finite variation of ' $X$ ' state parameter \\
$\mathrm{EGR}$ & Exhaust Gas Recirculation \\
$f$ & Friction factor \\
$h$ & Specific enthalpy $(\mathrm{kJ} / \mathrm{kg})$ \\
$k$ & Specific heat ratio \\
$L$ & Admission or exhaust stroke length $(\mathrm{m})$ \\
$m$ & Mass (kg) \\
$\dot{m}$ & Mass flow rate $(\mathrm{kg} / \mathrm{s})$ \\
\hline
\end{tabular}




\begin{tabular}{|c|c|}
\hline$M$ & Mach number of gases at valve inlet \\
\hline$n$ & Mol number \\
\hline$N$ & Engine speed (rpm) \\
\hline$R$ & Gas constant $(\mathrm{kJ} /(\mathrm{kg} \cdot \mathrm{K}))$ \\
\hline$S$ & Total entropy $(\mathrm{kJ} / \mathrm{K})$ \\
\hline$T$ & Temperature $(\mathrm{K})$ \\
\hline TDC & Top Dead Centre \\
\hline$t$ & Time (s) \\
\hline$Q$ & Heat $(\mathrm{kJ})$ \\
\hline$\dot{Q}$ & Heat flow rate $(\mathrm{kW})$ \\
\hline$x$ & Mol fraction \\
\hline$\dot{X}$ & Flow rate of ' $X$ ' state parameter or transferred energy \\
\hline \multicolumn{2}{|l|}{ Greek } \\
\hline$\alpha$ & Heat transfer coefficient $\left(\mathrm{kW} /\left(\mathrm{m}^{2} \cdot \mathrm{K}\right)\right)$ \\
\hline$\theta$ & Crank angle $\left(^{\circ}\right)$ \\
\hline$\rho$ & Density $\left(\mathrm{kg} / \mathrm{m}^{3}\right)$ \\
\hline \multicolumn{2}{|c|}{ Subscripts } \\
\hline$a$ & Air \\
\hline $\mathrm{adm}$ & Admission \\
\hline$d$ & Downstream of valve \\
\hline exh & Exhaust \\
\hline$f$ & Fuel \\
\hline gen & Generated \\
\hline$i$ & Chemical species number of reactants and combustion products \\
\hline in & Inlet \\
\hline$k$ & Chemical species number of combustion products \\
\hline$l$ & Number of borders \\
\hline out & Outlet \\
\hline$p$ & Combustion products \\
\hline$r$ & Reactants \\
\hline$u$ & Upstream of valve \\
\hline$w$ & Wall \\
\hline 0 & Standard reference: $T_{0}=298 \mathrm{~K}, p_{0}=1 \mathrm{~atm}$ \\
\hline $1,2,3,4$ & Points of Otto cycle (Figure 2) \\
\hline$\Delta p$ & Pressure drop \\
\hline
\end{tabular}

